\title{
The Discussion on Bird Hazard Prevention and Control Measures on the Transmission Lines
}

\author{
Shi Xiao, Tang Hui, Wang Xue, Zhan Shuguang, Li Yingxi, Han Lin, Li Na, Wang Qi, Zhao \\ Hengxin, Fang Bo
}

Fushun Power Supply Company, Liaoning Electric Power Company Limited, State Grid, China

Keywords: transmission lines; bird hazard prevention; technical measures; application effect

\begin{abstract}
The activities of the wild bird in the natural environment open space make the normal and stable technical performance of overhead transmission lines cause serious obstacles. The effective governance measures of bird hazard are active from thorn, the windmill anti-bird instrument and insulating repelling partition. Through the practical application on site, the optimal state of the exorcist is achieved, and the development of China's modern electric power industry has a profound practical impact.
\end{abstract}

\section{Introduction}

In recent years, China's natural ecological environment has been greatly improved with the increasing awareness of environmental protection. A number of breeding wild birds in China as well as the objective trend of the stock size are increasing, the bird in the open activity behaviors in natural environment also presents the objective trend of increasingly frequent. Meanwhile, wild birds' free behavior has brought the serious interference technology in the process of construction and operation of transmission line, and increased the power transmission line failure frequency in operation. Therefore, this paper will revolve around technical application of the bird hazard prevention and discuss it briefly in transmission lines.

\section{The Main Hazards of Birds}

In recent years, the activity behaviors of birds themselves daily field caused damaged. Due to the continuous improvement of the natural ecological environment, the number of memory size and breeding wild birds in China has produced a significant increasing trend, a direct result is that the overhead transmission line equipment is used in the actual operation process then faces the increasing intense bird hazard prevention technology stress.

The development characteristics of the birds' basic survival needs and the limitations characteristics of space hierarchy lead directly to the bird's own basic daily activities, extremely cause serious adverse impact on the normal operation of the transmission line. The frequent failure of transmission technology line causes the efficient and orderly development of China's modern energy industry serious bad block, the basic production and living practice are influenced and intervened seriously in China. The caused transmission lines breakdown of birds' basic daily activities is divided into three types:

Firstly, because some birds have a larger size, once the birds conduct basic activities in the distribution space of transmission line, interphase short circuit technical failure or the single-phase grounding fault technology is easy to be caused in the running transmission device.

Secondly, some birds chase prey on teaching activities in the sky, in the process, prey animal internal organs in its mouth is likely to occur random falling off phenomenon, once these organs drop to distribution within the space of the transmission line, the technical structure is likely to result in transmission line circuit technology problems.

Thirdly, some wild birds may be at some point in the process of random wandering or playing. As to curious psychology, they peck dynamic behavior randomly on technical artifacts of the transmission lines. For composite insulator or a transmission line, some birds peck dynamic 
behavior in the process of critical structures, it can lead to bare phenomenon in a mandrel structure of transmission line, or in other forms of more severe damage phenomenon, sometimes even the fierce power outage.

\section{Fault Phenomenon of Transmission Lines Caused by Bird Droppings}

Wild birds are bound to produce a certain amount of bird droppings outdoor. Because some birds prefer to habitat selection in distance and transmission line tower structure close to the position, or will live nest directly placed on the overhead transmission line tower structure, a direct result is that birds live in their day-to-day activities and produce waste or waste in the process of loss and accumulation within transmission lines space, frequent flashover fault phenomena is caused in transmission line, the technical performance stability of transmission lines is influenced seriously in actual using, even serious transmission line safety or operational accidents. Transmission line technical failure caused by nesting behavior of birds. In the process of basic survival and reproduction, birds need to construct a stable and safe long-term residence for themselves and build their nest activities based on instinct. Because some birds choose overhead transmission line as its own stable home at the top of the pole position, they will surely be at the top of the structure of overhead transmission line pole position selecting appropriate technology practice point to carry out activities to nest. Coincides with high winds, or the birds nest in the rainy season, the birds held in his mouth in the nest activities, all kinds of items is likely in the process of space flight, sinking falls to occur, some with conductivity image of nesting material, such as iron wire is extremely easy to fall, and it will delay between transmission lines cross phenomenon, short-circuit technical failure is caused in transmission lines.

\section{Bird Hazard Prevention Technical Measures in Transmission Lines}

\subsection{Active Expulsion Type Anti-bird Sting}

Repelling thorn is a kind of steel structure, the implementation is effective to prevent on transmission line pole nesting or stay behavior technology device, is often installed in high voltage transmission line tower structure component on the cross arm of the insulator. The anti bird technology have become more widely used in northwest China, repelling application stranded wire is as the main production of raw materials, using the pressure clamp to fix stranded wire clamp pressure with steel pipe material processing, and the other for the dispersed state, constituting external characteristics of the spurs in general technical conditions.

Repelling thorn has basic simple implementation, production technology in the process of practical application can also be equipped with copper ring gear and ancillary components, once the birds take activities close to power lines, bell file will release on sound and strong visual stimulation signal light signal to birds frightened and driven technology. In fact,

Repelling thorn technical measures in the process of practical application is also exist obvious technical shortcomings, its itself with spiral stationary internal technical structure characteristics is likely to be associated with rust, the device can't directly caused stretch, the function of the expected technical play is affected smoothly, at the same time, there is deformation phenomenon under the long-term used condition, even falling off phenomenon appears under the article of the transmission line close to the larger birds.

\subsection{Anti-bird Instrument on windmill}

The windmill type ejector is the earliest one in China's modern market environment. It has the advantages of simple application, quick and effective application and wide adaptability. Because of the convenience of the installation level, component has obtained the most adequate application in the field of transmission line protection.

The technology devices are installed on the overhead transmission line tower, with the aid of natural wind, birds are driven by windmills in the rotation process, then birds are shock and driven, and they cannot stay appeared on the transmission line. Because birds themselves are afraid of light, 
it is usually possible to structure the windmill blades with reflective material, with the aid of the windmill in the rotation, the process inflicts on birds optical drive in different direction of the stimulus, anti-bird instrument technology is achieved best.

\subsection{Insulation Anti- bird Baffle}

The insulation anti-bird baffle is the most common technology in the process of the transmission line with a lower level of cost. Insulation repelling clapboard is on the basis of conventional insulation board material and the simple technical processing link. It can be installed under the condition of stent assisted structure and the structure of the transmission line rail technology, with the aid of isolation between suspension insulator component and structure, the bird hazard prevention technology application is achieved effectively. The application of insulation for the bird hazard prevention and control work technological achievements are analyzed in northwest China, the expected effect of technology successfully is achieved. However, this component also has defects, such as the convenience of installation operation and the difficulty of maintenance and processing.

\section{Conclusions}

Around the application of bird hazard prevention technical measures in transmission lines, this paper discusses that birds activity causes transmission lines fault problem by classified analysis of the system, then the following specific expounds several applications of bird hazard prevention technology, a good job is well done for bird hazard prevention in transmission line, there are profound influence and support role for development of modern electric power industry in China.

\section{References}

[1] Chen Sheng, Li Wuhang. Application of anti-bird technology measures for transmission lines [J]. Zhejiang electric power. 2003 (02)

[2] Jiang Zhiying. Application of technology measures for the prevention of bird damage in transmission lines [J]. Science and technology innovation guide,2014 (27)

[3] Li Jiaxin, Xu Zheng, Zhou Wenhui. Research on the application of transmission line anti-bird technology measures [J]. China high-tech enterprise,2015 (08)

[4] Ma Zongren. Research on the application of transmission line anti-bird technology measures [J]. Technology and enterprises,2015 (21)

[5] Yin Qingyan. Discussion on the design technology of transmission line protection against bird damage [J]. Technology communication,2013 (20). 